\title{
Funciones y atribuciones del Servicio Nacional del Consumidor: avanzando hacia el origen
}

\author{
José Luis Guerrero Becar ${ }^{1}$
}

\section{RESUMEN}

La orgánica de protección de los consumidores comienza en Chile en 1932, desde esa fecha han existido distintos modelos normativos de protección de los derechos de los consumidores que han contemplado diseños contravencionales de carácter administrativos e incluso penales. El Servicio Nacional del Consumidor inicialmente se le limitó a funciones de educación e información, lo que se ha ido subsanando mediante reformas legales, la última de ellas por Ley No 21.081, que le permiten retomar funciones y atribuciones con las que en décadas anteriores contaron los órganos antecesores como el Comisariato, Superintendencia y Dirinco.

Palabras claves: Contravención - consumidor - Sernac - funciones y atribuciones.

\section{SUMMARY}

The organic of consumer protection begins in Chile in 1932, since that date there have been different regulatory models for the protection of consumer rights that have contemplated contraventional designs of an administrative and even criminal nature. The National Consumer Service was initially limited to functions of education and information, which has been remedied through legal reforms, the latter by law 21.081, that allow to Sernac to resume functions and powers that his predecessors such as the Commissariat, Superintendence and Dirinco.

Keywords: Contravention - consumer - Sernac - functions and powers.

1 Doctor y Máster en Derecho por la Universidad de Valencia, Master interuniversitario en Administración de Empresas (MBA) por las Universidades de Barcelona, Autónoma de Barcelona y Politécnica de Cataluńa, Abogado de la Pontificia Universidad Católica de Valparaíso, profesor titular de la Facultad de Derecho de la Pontificia Universidad Católica de Valparaíso. Correo: jose.guerrero@pucv.cl. ORCID 000002-8530-0330. 


\section{Introducción}

El Servicio Nacional del Consumidor (en adelante, Sernac) tiene sus primeros antecedentes institucionales en el ańo 1932, y desde esa época ha sido objeto de discusión legislativa y doctrinal tanto el diseño de protección de los derechos de los consumidores — que ha pasado del ámbito penal al contravencionalcomo las funciones que debe cumplir y las atribuciones con las cuáles debe contar el órgano estatal destinado a velar por la protección de dichos derechos. La discusión más reciente y relevante se produce con la última modificación normativa a la Ley No 19.496 de 1997 sobre protección de los derechos de los consumidores (en adelante LPDC), por la Ley No 21.081 de 2018 que fue objeto de una larga tramitación, que derivó en una declaración de inconstitucionalidad de aquellas normas del proyecto de ley que establecían al Sernac una función normativa y sancionatoria. Por lo señalado, se ha mantenido vigente la discusión sobre si se trata de un órgano sin atribuciones, estimamos que no obstante, las funciones que fueron vedadas por inconstitucionalidad, igualmente luego de la reforma por la Ley No 21.081 el Sernac cuenta con más herramientas para cumplir su función y creemos que es posible avanzar en la incorporación de la función administrativa sancionadora, sin reproche de constitucionalidad, en la medida que el legislador pueda distinguir su aplicación según el tipo de contravención y no establecer siu aplicación a toda contravención a la Ley No 19.496 y con ello podrá recuperar atribuciones que tuvieron sus antecesores orgánicos desde el año 1932. Para justificar esta hipótesis revisaremos la evolución normativa del Sernac y sus funciones y atribuciones luego de la modificaciones introducidas al Sernac por la Ley No 21.081.

\section{Antecedentes y breve revisión histórica del modelo institucional de protección de los consumidores en el Derecho chileno}

Los primeros antecedentes del Servicio Nacional del Consumidor se encuentran en el Decreto Ley 520 de 1932 que creó el Comisariato General de Subsistencias y Precios, dependiente del Ministerio del Trabajo. ${ }^{2}$ Este organismo estatal, fue creado bajo un periodo de excepción constitucional ${ }^{3}$ a efectos de controlar la industria y comercio, teniendo como objeto «asegurar a los habitantes de la República las más convenientes condiciones económicas de vida». En su normativa, se entregaba al Comisariato atribuciones interventoras de la actividad productiva y comercial, tales como la adquisición y control de la calidad y precios de los artículos de primera necesidad y de uso o consumo habitual, incluyendo facultades expropiatorias, al declararse de utilidad pública para el solo efecto de atender las necesidades imperiosas de la subsistencia del pueblo a predios agrícolas, empresas industriales y de comercio y a los establecimientos dedicados a la producción y distribución de artículos de primera necesidad.

El articulado del Decreto Ley No 520 de 1932, ya consideraba la noción de «consumidores», si bien no la definía, la mencionaba a efectos de incorporar a los Consejos Técnicos del Comisariato a los representantes de «los consumidores» (art. 15) y para la fijación de precios de venta «al consumidor» de artículos de primera necesidad por parte del Comisariato General y por los Comisariatos Departamentales (art. 23 y 25).

En 1953 se crea la Superintendencia de Abastecimiento y $\operatorname{Precios}^{4}$ que reemplaza al Comisariato General de Subsistencias y Precios, coincidiendo con la creación del Ministerio de Economía. Esta Superintendencia contaba con dos áreas: 1) Industria y Comercio, y 2) Transportes. La Superintendencia mantiene las

Decreto Ley No 520 de 1932.

Período histórico conocido como "La República socialista", liderado por una Junta Militar entre 4 de junio y el 13 de septiembre de 1932.

Decreto con Fuerza de Ley No 173, Hacienda, de 1953. 
atribuciones originales entregadas al Comisariato, en cuanto intervenir comercios que expendan productos de primera necesidad y controlar los precios de venta final, agregándosele expresamente la facultad de investigar y sancionar — administrativamente y mediante multas - diversas infracciones que hoy reconoceríamos como afectaciones a los derechos de los consumidores. En particular, se le entregan a la Superintendencia facultades de investigación y sanción administrativa directa a proveedores que incurran en infracciones durante la producción o comercialización de bienes de primera necesidad.

En 1960 se sustituye la Superintendencia de Abastecimiento y Precios por la Dirección de Industria y Comercio (Dirinco) ${ }^{5}$ organismo dependiente del Ministerio de Economía. Entre las facultades de Dirinco estaban la de fiscalizar, fijar precios, recibir denuncias de los consumidores y sancionar a los proveedores infractores de determinadas normativas. ${ }^{6}$ Asimismo, se le entregaban facultades normativas para poder fiscalizar la aplicación de la legislación vigente sobre comercio, costos, abastecimientos, precios y arriendos, y registros comerciales. ${ }^{7}$ Como se puede apreciar, Dirinco — antecesora del Sernac - contaba con atribuciones fiscalizadoras, normativas y sancionatorias.

Luego del golpe de estado de 1973 el régimen militar dictó una serie de normas de contenido económico, claramente reactivas a la tendiente centralización de la economía en el gobierno de la Unidad Popular, entre otras, se dictó el Decreto Ley No 211 de 1973 sobre libre competencia y el Decreto Ley No 280 de 1974 sobre normas en resguardo de la actividad económica nacional que categorizó las contravenciones a los derechos de los consumidores como delitos de competencia de los Juzgados del Crimen, cambiando el foco de persecución desde la autoridad administrativa —en ese entonces Dirinco- a los propios consumidores, quienes quedan con la legitimación activa para solicitar la tutela de sus derechos ante los tribunales de justicia. Así se señala en las motivaciones del Decreto Ley No 280 lo siguiente: «5 Que el Supremo Gobierno está interesado en que sea el propio consumidor el que supervigile el cumplimiento de las disposiciones del presente decreto ley». El modelo normativo seguido fue de persecución penal, el

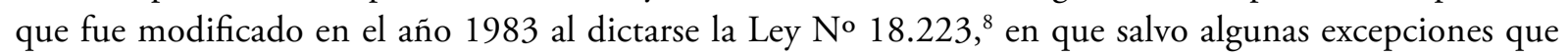
siguieron tipificados como delitos, las contravenciones a los derechos de los consumidores pasaron a un sistema de infracciones, sancionadas con multas y de conocimiento de los Juzgados de Policía Local en que la legitimidad activa sigue entregada al propio consumidor afectado. ${ }^{9}$

En 1990 se crea el Servicio Nacional del Consumidor (Sernac), ${ }^{10}$ en sustitución —más bien meramente denominativa - de Dirinco y Sernac recoge la situación existente a 1990 en cuanto se habían eliminado paulatinamente las facultades en materias investigativas, fiscalizadoras y sancionatorias que antes ejercía Dirinco.

Decreto con Fuerza de Ley No 242, Economía, de 1960.

Esto porque si bien el Decreto con Fuerza de Ley No 242, Economía, de 1960 no lo mencionaba expresamente, en su Art. 6 letra e) trasladó al director de Industria y Comercio las atribuciones vigentes a 1960 que correspondían al superintendente de Abastecimientos y Precios por aplicación del Decreto Ley No 520 de 1932, cuyo texto refundido se encontraba en el Decreto Economía No 1262 de 30 de diciembre de 1953. Por lo señalado, se trasladó al director, entre otras, la siguiente atribución sancionadora: «art. 22, k) Sancionar con multa o comiso el expendio de artículos adulterados o nocivos."

7 Art. 6 del Decreto con Fuerza de Ley No 242, Economía, de 1960 disponía entre las funciones y atribuciones de la Dirección de Industria y Comercio: «d) Dictar normas para la ejecución de las actividades señaladas en las letras precedentes, a través de todo el territorio nacional, por intermedio del Departamento de Oficinas Zonales».

$8 \quad$ Ley No 18.223 de 1983.

9 Sobre el cambio de paradigma de persecución desde una visión penal a una infraccional de conocimiento de Juzgados de Policía Local, Guerrero Becar en Revista de Derecho de la Pontificia Universidad Católica de Valparaíso, núm. 26, Valparaíso, pp. 165-185.; Guerrero Becar " en Guzmán Brito (2008) pp. 433-453.

10 Art. 5 de la Ley 18.959 de 1990 Sustituyese, en el Decreto con Fuerza de Ley N²42, de 1960, todas las menciones a la «Dirección de Industria y Comercio» por la denominación «Servicio Nacional del Consumidor». Toda referencia que las leyes vigentes, efectúen a la «Dirección de Industria y Comercio» se entenderán hechas al «Servicio Nacional del Consumidor». 
En 1997 un hito relevante es la dictación de la Ley No 19.496 que establece normas sobre protección de los derechos de los consumidores ${ }^{11}$ que incorpora en su Título V, artículos 57 a 60, normas sobre Sernac disponiendo que «El Servicio Nacional del Consumidor deberá velar por el cumplimiento de las disposiciones de la presente ley y demás normas que digan relación con el consumidor, difundir los derechos y deberes del consumidor y realizar acciones de información y educación del consumidor». ${ }^{12}$

De la revisión del texto legal, es fácil advertir que las atribuciones o funciones principales que se le entregaron al Sernac para cumplir su objeto, se circunscribieron a la realización de estudios, promoción de investigaciones y divulgación de información. Si bien, se le entrega la facultad de velar por el cumplimiento de otras normas que digan relación con el consumidor, inmediatamente se restringe esta atribución, ya que solo puede ser ejercida cuando esa facultad no está entregada al conocimiento y resolución de otros organismos o instancias jurisdiccionales, caso en el cual, el Sernac solo puede denunciar las posibles infracciones ante esas otras instituciones.

Es claro que el Sernac bajo el diseño de la LPDC en su texto original de 1997 se diseñó como un servicio administrativo de información a los consumidores, sin atribuciones para una participación directa en defensa de los consumidores, salvo dos excepciones: Puede realizar una labor facilitadora de conciliaciones en conflictos entre proveedores y consumidores — la mal llamada "mediación del Sernac» ${ }^{13}$ — o bien, puede actuar directamente en casos que afecten el interés general de los consumidores, que pasa a constituirse en el único caso en que se le entrega al Sernac legitimación activa directa para comparecer ante los Tribunales de Justicia. ${ }^{14}$

Luego, en el año $2004^{15}$ se incorporan a la lpdc acciones de protección del interés colectivo difuso de los consumidores, comenzando el Sernac a tener un mayor protagonismo al entregársele legitimación activa en estas materias. ${ }^{16}$

La necesidad de dotar al Sernac de mayores atribuciones para cumplir su papel de protección de los derechos de los consumidores, rompiendo, con el paradigma anunciado en el Decreto Ley No 280 de 1974 en cuanto deben ser los propios consumidores los que deben velar por la protección de sus derechos, ha sido un tema en constante debate en materia legislativa, que tuvo su punto más álgido y trascendente en la tramitación del proyecto de Ley para fortalecer las facultades del Sernac, presentado como mensaje presidencial el 3 de junio de $2014^{17}$ y que terminara con un texto aprobado por el Congreso Nacional en el mes de octubre de $2017^{18}$ que entregaba —o restituía si consideramos la situación histórica de los antecesores del Sernac, aquí brevemente relatadas - funciones en materia fiscalizadora, normativa y sancionadora.

$11 \quad$ Ley No 19.496 de 1997.

12 Art. 58 de Ley No 19.496 de 1997 (texto original).

13 Decimos «mal llamada función mediadora», originalmente establecida en el Art. 50 de la ley 19.496, ya que la mediación como mecanismo de resolución alternativa de conflictos, supone que se realice ante un tercero neutral, el que no puede plantear bases de solución —éstas deben nacer de las propias partes en el proceso de mediación - En este caso, por el contrario, quien actuaría de «mediador», es el Servicio Nacional del Consumidor, que por definición normativa debe velar por el interés de los consumidores, y además puede en estos mismos casos, si se afecta el interés de los consumidores, perseguir al proveedor ante los tribunales de justicia competente. La doctrina, igualmente, se refiere a esta atribución como «instancia mediadora del Sernac», por ejemplo, Cortez Matcovich (2004) p.16.

14 Art. 54 de Ley No 19.496 de 1997 (texto original).

Ley No 19.955 de 2004

Art. 51, No 1, letra a) de la Ley 19.496 de 1997, modificado por la Ley 19.955 de 2004.

Proyecto de ley contenido en boletín $\mathrm{N}^{\circ}$ 9.369-03.

18 El proyecto fue remitido por la Cámara de Diputados para el control de constitucionalidad el día 26 de octubre de 2017. 
Sin embargo, dicho texto legal fue objeto de un control de constitucionalidad preventivo por parte del Tribunal Constitucional, el que se pronunció por sentencia de fecha 18 de enero de 2018, declarando inconstitucionales diversas normas del proyecto de ley aprobado por el Congreso Nacional, en particular, aquellas normas que entregaban funciones en materias normativas y sancionadoras. ${ }^{19}$ La declaratoria de inconstitucionalidad ha sido objeto de diversas críticas, en especial de especialistas en derecho administrativo que la han catalogado como un retroceso en el derecho administrativo sancionador. ${ }^{20}$

La reforma a la LPDC efectuada por la Ley No 21.081, fue publicada en el Diario Oficial el día 13 de septiembre de $2018,{ }^{21}$ estableciéndose en sus normas transitorias un cronograma de entrada en vigencia de sus distintas normas, entre otras, las facultades para aplicar multas por parte del Sernac, que distingue por regiones, siendo la más tardía en entrar en vigencia, la Región Metropolitana 24 meses después de la publicación, esto es, el 13 de septiembre de 2020.

\section{Naturaleza jurídico-institucional del Servicio Nacional del Consumidor}

De acuerdo al Art. 57 de la LPDC, el Sernac se constituye como un servicio público descentralizado, con personalidad jurídica y patrimonio propio, sujeto a la supervigilancia del presidente de la República a través del Ministerio de Economía, Fomento y Turismo.

La reforma del año 2018 a la LPDC define al Sernac como una institución fiscalizadora en los términos del Decreto Ley No 3.551 de 1981 (art. 57 inciso 20 LPDC), caracterización con la que no contaba este Servicio desde su creación en 1990, y que le permite retomar una función con la que contaron sus antecesores institucionales, según revisamos previamente. Sin embargo, la referencia al Decreto Ley No 3.551 de 1981, es solo en términos remuneracionales, atendido que dicha norma no entrega facultades fiscalizadoras, sino que solo define remuneraciones especiales para los órganos de la Administración del Estado que tienen carácter de «instituciones fiscalizadoras», debiendo revisarse en la LPDC si efectivamente se le han entregado al Sernac facultades de fiscalización.

19 Sentencia del Tribunal Constitucional de fecha 18 de enero 2018, Rol 4012-2017, disponible en www.tribunalconstitucional.cl

20 Esta es una visión que no compartimos, ya que el órgano administrativo debe necesariamente cumplir con un papel imparcial, lo que no cumple cuando reúne todas las facultades propias de la investigación, juzgamiento y sanción. Si bien existen otros órganos de la administración que tienen esas atribuciones, como algunas superintendencias, en este caso, a diferencias de esos, el órgano de la administración tiene un fin definido de proteger a una de las partes. En otros casos, el interés es el cumplimiento del orden económico, no resolver en relaciones entre particulares en que, respecto de uno de ellos, el juzgador tiene la obligación de protegerlo. Excede de los objetivos de este capítulo profundizar en la fundamentación, pero siendo una discusión relevante, y por lo reciente de la sentencia aún no contamos con artículos científicos sobre el punto, mencionamos algunos comentarios y fundamentaciones relativas a este debate, que se inició incluso antes de la sentencia del Tribunal Constitucional. Cordero "Jurisdicción en la Administración: una tramposa confusión» en Mercurio Legal de 30 de octubre de 2017; Soto «El Tribunal Constitucional y las sanciones administrativas en el fallo sobre el Sernac», en Mercurio Legal de 19 de enero de 2018 ; Cordero "El problema de identidad del Derecho Administrativo chileno» en Mercurio Legal de 27 de febrero de 2018. En este último comentario, el autor señala que «Lo grave de la sentencia del TC en el caso Sernac es que demolión, sin un estándar de justificación lo suficientemente robusto, un modelo de Derecho Administrativo democrático que se había venido construyendo en la última década y media, cuyo protagonista había sido precisamente la jurisprudencia judicial, constitucional y contralora». En sentido de apoyo a la sentencia: Alvear "¿ Ogro filantrópico o Sernac?», en Mercurio Legal de 2 de febrero de 2018; vergara, ALEjandro: «Sanciones, despotismo e identidad del derecho administrativo», en Mercurio Legal de 20 de marzo de 2018. Todos estos comentarios están disponibles en www.mercurio.com/legal.

21 La ley No 21.081 de 2018 que reforma a la Ley 19.496 de 1997, en definitiva, fue publicada en el Diario Oficial el día 13 de septiembre de 2018. La demora desde la sentencia del Tribunal Constitucional, se debió a las dificultades que produjo la interpretación de los alcances de la sentencia ya que existían declaraciones de inconstitucionalidad en la parte declarativa que no se seńalaban en la parte resolutiva, lo que conllevó a que la Contraloría General de la República representara el decreto promulgatorio por apreciar diferencias entre el texto del proyecto de ley remitido para su promulgación y la sentencia del Tribunal Constitucional, que llevó al presidente de la República a presentar ante el mismo Tribunal Constitucional una cuestión de constitucionalidad sobre el decreto promulgatorio que fue resuelta por éste por sentencia de fecha 5 de julio de 2018, en causa rol 4727/2018. 
El Sernac se desconcentra en direcciones regionales y en cuanto a su dirección nacional como direcciones regionales está afecto al Sistema de Alta Dirección Pública establecido en la ley No 19.882 .

\section{Funciones y atribuciones del Servicio Nacional del Consumidor}

El art. 58 LPDC dispone que Sernac deberá velar por el cumplimiento de las disposiciones de la ley y demás normas que digan relación con el consumidor, difundir los derechos y deberes del consumidor y realizar acciones de información y educación del consumidor. Además, se le entregan una serie de funciones ${ }^{22}$ específicas, alguna de ellas más bien atribuciones. A continuación, pasamos a revisar aquellas que son más relevantes o son inéditas luego de la modificación a la LPDC efectuada por la Ley 21.081/2018. ${ }^{23}$

\subsection{Fiscalización}

De acuerdo al Art. 58 letra a) el Sernac tiene la función de "fiscalizar el cumplimiento de las disposiciones de la presente ley y de toda la normativa de protección de los derechos de los consumidores», es una función que no estaba contemplada en la norma original.

Para el cumplimiento de esta nueva función, la ley entrega una serie de atribuciones a los funcionarios del Servicio respecto de medidas intrusivas, que le permiten fiscalizar in situ afectaciones a los derechos de los consumidores, cumpliendo con medidas de garantía mínima a los fiscalizados, como información del objeto de la fiscalización y entrega de copia de las actas de fiscalización.

De este modo, durante los procedimientos de fiscalización se obliga a los proveedores y a sus representantes a otorgar todas las facilidades para que éstos se lleven a efecto, sin que puedan negarse a proporcionar la información requerida sobre los aspectos materia de la fiscalización.

La norma dispone en garantía del fiscalizado que los funcionarios siempre deben informar la materia especifica objeto de la fiscalización y de la normativa pertinente dejando copia del acta levantada y limitando las diligencias a las estrictamente indispensables y proporcionales al objeto de la fiscalización, pudiendo ser denunciadas las conductas abusivas de los funcionarios ante el director regional del Servicio. ${ }^{24}$

Se entregan a los funcionarios del servicio facultades intrusivas, en cuanto "pueden en sus labores inspectoras ingresar a inmuebles en que se desarrollen actividades objeto de fiscalización, tomar registros del sitio o bienes fiscalizados, levantar actas y dejar testimonio en ellas de quienes se encontraren en el lugar de la fiscalización y, en general, proceder a la ejecución de cualquier otra medida tendiente a hacer constar el estado y circunstancias de las actividades fiscalizadas. Cuando se trate de fiscalización de sitios

22 El legislador en el caso de la LPDC utiliza la voz «funciones». En otras leyes se utilizan las voces potestades, competencias, atribuciones o facultades. De acuerdo al Diccionario Panhispánico del español jurídico, debe entenderse por función pública: «Competencia o potestad de la Administración pública. Tarea que corresponde realizar a una institución o entidad pública o a un funcionario». Muñoz Machado (2017) p. 1056.

23 Otras funciones incorporadas a la Ley No 19.046 de 1997 por la Ley No 21.081 de 2018 al Sernac son: función de información y educación de los consumidores (art. 58 inc. $2^{\circ}$, letra h), función de realización de análisis y estudios sobre productos en laboratorios o entidades especializadas (art. 58 inciso $2^{\circ}$, letra i LPDC), función informativa (art. 58 inc. 2, letra j LPDC), atribución para realización y promoción de estudios (art. 58, inc. 2ª letra k LPDC), función de llevar un registro público de sentencias de jueces de policía local y jueces de letras y resoluciones sancionatorias de órganos administrativos (art. 58, inciso $2^{\circ}$, letra 1 y 58 bis LPDC) y remisión general a las demás funciones y atribuciones que le asigne la LPDC u otras leyes (art. 58 inc. 2, letra ń LPDC).

24 Art. 58, letra a), inciso $3^{\circ}$ de la Ley 19.496 de 1997. 
web, los proveedores estarán obligados a facilitar los antecedentes relativos a éste que sean solicitados por el respectivo funcionario del Servicio, los que deberán ser entregados en formato digital». ${ }^{25}$

Se advierte que la generalidad de la expresión "cualquier otra medida», puede provocar dificultades en los procesos de fiscalización, al ser el propio fiscalizador quien para hacer constar el hecho que está fiscalizando determina la aplicación de "cualquier otra medida». Estimamos que la fiscalización cumplirá con estándares de garantías constitucionales, solo en la medida en que se cumpla con los principios generales de derechos fundamentales y en la medida que se cumpla con la Ley No 19.880 sobre bases del procedimiento administrativo.

Por otro lado, en el caso de fiscalización de sitios web se deberá tener especial cuidado con la solicitud de antecedentes que puedan estar protegidos por propiedad industrial. Lo anterior, lo prevé la reforma de 2018, al disponer en el artículo 59 ter de la LPDC que los funcionarios y demás personas que presente servicios en Sernac están obligados a guardar reserva de toda información, dato o antecedentes de la cual puedan tomar conocimiento en el ejercicio de sus labores, estableciendo responsabilidades administrativas y penales. ${ }^{26}$

En estos casos de acciones intrusivas, solo en caso de oposición, los funcionarios pueden solicitar al juez de policía local correspondiente al local objeto de la fiscalización, el auxilio de la fuerza pública. La oposición debe ser certificado por el fiscalizador (art. 58, letra a, inciso 5 LPDC).

Se debe tener presente que los funcionarios del Sernac en funciones de fiscalización se transforman en ministros de fe según lo dispone el art 59 bis LPDC, por lo que en dicho carácter certificarán la oposición del proveedor y además les corresponde calificar la justificación que pueda entregar el proveedor a su negativa, sancionándose la oposición injustificada con multa de hasta 750 Unidades Tributarias Mensuales, por lo que en el procedimiento judicial para aplicar la multa, dos elementos esenciales como son el hecho de la oposición y la calificación de la justificación, serán determinados por funcionarios del Sernac. ${ }^{27}$

Advertimos que esta atribución entregada a los funcionarios del Sernac puede conllevar vulneraciones al debido proceso, que se inicie como consecuencia de la acción de fiscalización, ya que queda entregado al ente fiscalizador tanto la certificación de la oposición como la calificación de la justificación entregada por el proveedor para oponerse. Por tanto, si tal calificación es exclusiva del Senac, al juez de policía local que le corresponda conocer del proceso sancionatorio, una vez calificada como injustificada la negativa del proveedor, solo le quedará aplicar una multa y graduar ésta, pero en caso alguno podría eximir de su aplicación, ya que los supuestos estarían acreditados y determinados por el servicio a priori en la acción de fiscalización, salvo que el proveedor pueda probar en contra de la presunción legal, ya que ésta es simplemente legal.

25 Art. 58, letra a), inciso $4^{\circ}$ de la Ley 19.496 de 1997.

26 Normas similares se han establecido para otros órganos fiscalizadores que pueden recibir información confidencial o de secreto industrial o comercial como, por ejemplo, en el caso de la Fiscalía Nacional Económica, en que se contempla que el Fiscal Nacional Económico de oficio o a petición del interesado puede disponer que ciertos antecedentes tengan el carácter de reservado, disponiendo además la obligación a los funcionarios de guardar reserva de toda información, dato o antecedente que conozcan en el ejercicio de sus cargo, sancionándose su vulneración como un delito además de las sanciones administrativas que pudieren proceder. Art. 39, letra a) y Art. 42 del Decreto Ley No 211 de 1973.

27 El art. 59 bis de la Ley 19.496 de 1997 dispone que «Los hechos establecidos por dicho ministro de fe constituirán presunción legal en cualquiera de los procedimientos contemplados en el párrafo $2^{\circ}$ del Titulo IV de esta ley». Sin embargo, esa atribución general debe entenderse restringida a los procedimientos ante jueces de policía local, esto porque el párrafo $2^{\circ}$ del Título IV del proyecto de ley original de reforma a la Ley 19.496 de 1997 por la Ley 21.081 de 2018 referido a «la mediación individual, la conciliación y el procedimiento sancionatorio instruido por el Servicio Nacional del Consumidor» fue declarado inconstitucional en todos sus artículos, por lo que el párrafo $3^{\circ}$ del proyecto de ley, pasó a ser el $2^{\circ}$ de la ley definitiva y éste se refiere al procedimiento ante los Juzgados de Policía Local. 
La situación advertida creemos que se manifestaba con mayor intensidad en el proyecto de reforma original, en que se entregaban al propio Sernac facultades sancionadoras, con ello, el propio servicio, investigaría, calificaría y sancionaría. Al declararse la inconstitucionalidad de las normas sancionadoras del servicio, esta crítica se aminora, en cuanto ahora deberá ser el juez de policía local el que lleve adelante el procedimiento sancionatorio y deba determinar la multa.

En todo caso, se contempla una situación de excepción cuando la fiscalización se realice a micros o pequeñas empresas en los términos del inciso segundo del artículo segundo de la Ley No 20.416, en la medida que dichas empresas que no hayan sido sancionadas por la misma infracción en los últimos doce meses. En este caso, si no concurre alguna de las circunstancias agravantes previstas en el artículo 24 , se les podrá conceder un plazo de hasta diez días hábiles para dar cumplimiento a las normas respectivas, lo que deberá ser acreditado ante el Servicio Nacional del Consumidor (art. 58, letra a, inciso 7o LPDC).

Por último, respecto de esta función, se establece por la LPDC que el Sernac desarrollará sus actividades de fiscalización en conformidad a un plan que elaborará anualmente, en el que priorizará aquellas áreas que involucren un mayor nivel de riesgo para los derechos de los consumidores, siendo públicas las directrices generales de dicho plan. ${ }^{28}$

En este sentido el Sernac, en cumplimiento de la modificación legal que comentamos, el 23 de abril de 2020 por Resolución Exenta No 370 del director del servicio, se aprobó la Política de Fiscalización del Sernac. Igualmente, el servicio comunica en su sitio web sus planes anuales de fiscalización. A vía de ejemplo, el Plan Anual de Fiscalización para el año $2020^{29}$ señala que «las actividades de fiscalización, se concentrarán en fiscalizar el cumplimiento de un conjunto de obligaciones legales por parte de proveedores que participen en submercados donde el servicio haya identificado riesgos de vulneración de estas obligaciones. El ejercicio 2020 se hace principalmente a partir de los reclamos recibidos por el Sernac durante el año 2019.» ${ }^{30}$

Esta es una norma relevante, ya que vincula la función fiscalizadora a una labor preventiva y educativa ya que, al establecer directrices públicas de planes de fiscalización y riesgo, incentiva a que los proveedores puedan adoptar las medidas necesarias para dar cumplimiento a la normativa, esto unido, a la creciente cultura de incorporar en grandes empresas el cumplimiento normativo, también denominado comúnmente, aplicando anglicismos, como «compliance».

\subsection{Interpretación administrativa}

El art. 58 letra b) de la LPDC dispone que el Sernac debe «Interpretar administrativamente la normativa de protección de los derechos de los consumidores que le corresponde vigilar. Dichas interpretaciones solo serán obligatorias para los funcionarios del servicio».

La facultad de interpretación administrativa de la normativa no es una novedad en el Derecho chileno, y es una atribución que se entrega frecuentemente a organismos fiscalizadores.

Según Alejandro Guzmán Brito la primera facultad de interpretación administrativa en el Derecho chileno fue entregada al contralor general de la República al entregársele un poder dictaminador obligatorio

28 Art. 58, letra a), inciso 8 Ley No 19.496 de 1997.

29 Sernac: «Directrices plan anual de fiscalización 2020», disponible en https://www.sernac.cl/portal/618/articles-55703_archivo_01.pdf

30 El plan de fiscalización 2019 consideró los mercados del retail, ventas por Internet, transporte y servicios básicos.p. 3. 
para los funcionarios públicos, siendo el prototipo de los casos posteriores de atribución de potestades administrativas. Estas últimas, según el propio autor, tendrían su explicación, paradojalmente, en limitar el poder dictaminador del contralor general de la República. La hipótesis de Guzmán Brito es que los gobiernos se interesaron en la potestad de interpretación administrativa — normalmente entregada a funcionarios de exclusiva confianza del presidente de la República- como una manera de restringir la influencia de la Contraloría General de la República en la interpretación de leyes administrativas, atendido que cada vez que una ley otorga a determinado jefe de servicio el poder de interpretar cierto sector de la legislación, con ello sustraería el mismo poder al contralor. ${ }^{31}$

Por lo anterior, cabe preguntarse si ésta facultad interpretativa entregada al servicio, excluye a la propia Contraloría de su facultad dictaminadora.

La Contraloría ha dictaminado inhibiendo su propia atribución interpretativa cuando la ley entrega esa facultad en una materia específica a otro órgano de la administración. Así, por ejemplo, lo ha señalado recientemente un dictamen del contralor, refiriéndose a la facultad interpretativa de la Superintendencia de Insolvencia y Reemprendimiento. ${ }^{32}$

Entendemos que en el caso de la LPDC, como la interpretación que pueda realizar el servicio muy probablemente no dirá relación con las materias que son de competencia exclusiva del contralor general de la República, ${ }^{33}$ sino con interpretación de normas que se relacionen con proveedores, más que contiendas con la Contraloría, se presentarán cuestiones de interpretación entre el servicio y los tribunales de Justicia, lo que per sé además inhibe la actuación de la Contraloría General de la República.

La propia LPDC es clara en definir los sujetos pasivos de la obligación de seguir la interpretación del servicio, restringiéndolos a sus funcionarios, por ello todo proveedor o consumidor que no comparta esa interpretación podrá cuestionarla ante los tribunales de Justicia, pero, creemos que no podrán hacerlo ante el contralor general de la República, por las razones antes indicadas.

Cabe tener presente que la atribución de potestad interpretativa al servicio, es más amplia que interpretar solo la LPDC, ya que utiliza la ley en su artículo 58 inciso 2o, letra b) la expresión genérica "Interpretar administrativamente la normativa de protección de los derechos de los consumidores que le corresponde vigilar". Sin embargo, previamente en el encabezado del Art. 58 LPDC -inciso $1^{\text {o- }}$ al definir las competencias genéricas del Servicio Nacional del Consumidor, señaló: «El Servicio Nacional del Consumidor deberá velar por el cumplimiento de las disposiciones de la presente ley y demás normas que digan relación con

31 Guzmán Brito (2014) pp.2, 19-20.

32 «En consecuencia, dadas las consideraciones precedentes, y en atención a que la consulta de la especie dice relación con la interpretación de preceptiva relativa a los honorarios de los mencionados síndicos o liquidadores -materia contenida en los artículos 33 y siguientes del Libro IV del Código de Comercio, y 39 y 40 de la ley N ${ }^{\circ} 20.720$-, incidiendo de ese modo en una atribución propia de la Superintendencia de Insolvencia y reemprendimiento", corresponde a ese organismo pronunciarse sobre el asunto planteado. Transcríbase a la Dirección de Presupuestos. Saluda atentamente a Ud. Jorge Bermúdez Soto. Contralor general de la República. Dictamen del contralor general de la República, No 18442 de 19 de mayo de 2017, disponible en www.contraloria.cl.

33 Artículo $6^{\circ}$ de la Ley Orgánica de la Contraloría General de la República, Ley No 10.336 de 1952: «Corresponderá exclusivamente al contralor informar sobre derecho a sueldos, gratificaciones, asignaciones, desahucios, pensiones de retiro, jubilaciones, montepíos y, en general, sobre los asuntos que se relacionen con el Estatuto Administrativo, y con el funcionamiento de los servicios públicos sometidos a su fiscalización, para los efectos de la correcta aplicación de las leyes y reglamentos que los rigen. Del mismo modo, le corresponderá informar sobre cualquier otro asunto que se relacione o pueda relacionarse con la inversión o compromiso de los fondos públicos, siempre que se susciten dudas para la correcta aplicación de las leyes respectivas. La Contraloría no intervendrá ni informará los asuntos que por su naturaleza sean propiamente de carácter litigioso, o que estén sometidos al conocimiento de los tribunales de Justicia, que son de la competencia del Consejo de Defensa del Estado, sin perjuicio de las atribuciones que, con respecto a materias judiciales, reconoce esta ley al contralor. De acuerdo con lo anterior, solo las decisiones y dictámenes de la Contraloría General de la Republica serán los medios que podrán hacerse valer como constitutivos de la jurisprudencia administrativa en las materias a que se refiere al artículo 1 ». 
el consumidor (...)», con ello queda claro que la facultad de interpretación administrativa no se restringe solo a la LPDC, sino que es aplicable a toda norma que diga relación con el consumidor y que al Sernac le corresponde vigilar.

Por lo señalado, toda norma, legal o reglamentaria, que tenga relación con derechos de los consumidores podría ser objeto de interpretación administrativa por parte del Sernac, ampliando de manera impensada su facultad de interpretación, ya que, por ejemplo, normas tales, como ley de bancos, seguros y otras contienen disposiciones relativas a consumidores, por lo que una cuestión de competencia se podrá presentar si otro órgano de la administración, en el ámbito de su competencia específica también pueda normar ámbitos de interés de los consumidores y, a su vez, también tenga su propia potestad de interpretación administrativa.

En este último caso, estimamos que deberá primar la interpretación que realice el organismo sectorial, por ejemplo, la Comisión para el Mercado Financiero, sobre las normas especiales que son objeto de su fiscalización e interpretación administrativa, opción que se reafirma en el hecho que la propia LPDC restringe la obligatoriedad de la interpretación administrativa que pudiere realizar el Servicio Nacional del Consumidor, a sus propios funcionarios, con lo cual, en el evento que Servicio Nacional del Consumidor interpretara una norma que diciendo relación con consumidores, está también bajo el ámbito interpretativo de otro órgano de la administración, tal interpretación que pudiere realizar el Servicio Nacional del Consumidor claramente no sería obligatoria para terceros y ni siquiera para los funcionarios del otro organismo que cuenta con la atribución específica de interpretarla.

\subsection{Proposición normativa}

El Art. 58 inciso 20, letra c) de la LPDC entrega esta función al Servicio Nacional del Consumidor, disponiendo que éste puede «Proponer fundadamente al presidente de la República, a través del Ministerio de Economía, Fomento y Turismo, la dictación, modificación o derogación de preceptos legales o reglamentarios en la medida que ello sea necesario para la adecuada protección de los derechos de los consumidores. El Servicio acompañará a la propuesta un informe técnico que exprese los antecedentes y razones en que se funda».

Más que una función, es propiamente una atribución que se le otorga al Servicio Nacional del Consumidor de proponer cambios normativos, sean legales o reglamentarios, lo que debe realizar al presidente de la República, a través del Ministerio de Economía, Fomento y Turismo, en cuanto el presidente tiene potestad reglamentaria, y además puede presentar iniciativas legislativas al Congreso Nacional.

Esta atribución es coherente con su finalidad de velar por la adecuada protección a los consumidores, y si bien, es una norma que se incorpora en la reforma 2018, igualmente se podía ejercer a través de los canales institucionales correspondientes, ya que, como órgano especializado, toda materia relativa a normativa relativa a los derechos de los consumidores, requiere por prudencia normativa, la consulta u informe a este organismo. En todo caso, esta atribución de proposición de cambios normativos, no es inédita en nuestro derecho ya que otras instituciones cuentan con normas similares, como es el caso del tribunal de defensa de la libre competencia, y la propia Corte Suprema de Justicia y tribunales de Alzada (Cortes de Apelaciones), que con un objetivo similar, pueden dar cuenta de dudas y dificultades que presente la aplicación de la ley, y ello se realiza con el sentido de proposición indirecta a cambios normativos. ${ }^{34}$

34 Art. 5 del Código Civil: «La Corte Suprema de Justicia y las Cortes de Alzada, en el mes de marzo de cada año, darán cuenta al presidente de la República de las dudas y dificultades que les hayan ocurrido en la inteligencia y aplicación de las leyes, y de los vacíos que noten en ellas»; y Art. 102 No 4 del Código Orgánico de Tribunales: «El primer día hábil de marzo la Corte Suprema iniciará sus funciones en audiencia pública, a la cual deberán concurrir su fiscal judicial y los miembros y fiscales judiciales de la Corte de Apelaciones de Santiago. El presidente 


\subsection{Indagación}

Hemos denominado función indagatoria, a lo establecido en el Art. 57 inciso 2o, letra d) de la LPDC, que más que una función, es una atribución o potestad necesaria o funcional para poder cumplir con la función fiscalizadora.

La norma dispone que el Servicio Nacional del Consumidor, tiene por función «Citar a declarar a los representantes legales, administradores, asesores y dependientes de las entidades sometidas a su fiscalización, así como a toda persona que haya tenido participación o conocimiento respecto de algún hecho que estime necesario para resolver un procedimiento sancionatorio, o tomar la declaración respectiva por medios que permitan asegurar su fidelidad. Si el citado debidamente apercibido no comparece, sin mediar justificación plausible, el juzgado de policía local competente podrá ordenar su arresto hasta su comparecencia».

Como se podrá entender, el Servicio Nacional del Consumidor no puede tener por función —como lo define el art. 58 inciso 20 LPDC-, esto es, como competencia de su esencia, el citar a representantes de fiscalizados. Esta es una atribución o potestad que le permitirá cumplir sus funciones esenciales, pero no es una función en si misma. No cabe por tanto confundir la función con la potestad para cumplir la función, como lo hace en este caso el legislador.

Atendido que el Tribunal Constitucional declaró inconstitucional la función sancionatoria del Sernac, llama la atención que no haya declaro igualmente inconstitucional esta norma, ya que incorpora la frase "respecto de algún hecho que estime necesario para resolver un procedimiento sancionatorio», con lo cual se entiende que la facultad de citar está dado en ese contexto que el Sernac no puede realizar, por lo que es probable que genere discusión jurisprudencial cuando se ejerza por parte del Sernac si citare a cualquier persona que no tenga la calidad de proveedor.

Respecto de los proveedores, estimamos que la norma es perfectamente aplicable ya que todo proveedor está sujeto a la fiscalización del Sernac por lo que es posible citarlo para recabar antecedentes, no para aplicar sanciones directamente ya que tiene vedada esa facultad el Sernac, sino que poder iniciar un procedimiento infraccional ante el órgano jurisdiccional competente.Lo anterior se podría enmarcar dentro de las «potestades implícitas» que tendría todo órgano de la administración del Estado para poder cumplir con sus competencias. ${ }^{35}$

\subsection{Información y consulta}

De acuerdo al Art. 58, inciso 2o, letra e) es función del Sernac: «Proporcionar información y absolver las consultas del Ministerio de Economía, Fomento y Turismo, del Tribunal de Defensa de la Libre Competencia, de la Fiscalía Nacional Económica y demás organismos relacionados con la protección de los derechos de los consumidores».

Esta función no estaba en el texto original de la LPDC, y es propia de muchos órganos de la administración del Estado y también es común en el derecho comparado. ${ }^{36} \mathrm{Si}$ bien, en lo práctico, pudiere considerarse innecesario incorporarse atendido un principio jerárquico, tiene mayor sentido desde la reforma del 2018,

de la Corte Suprema dará cuenta en esta audiencia: $4^{\circ}$ De las dudas y dificultades que hayan ocurrido a la Corte Suprema y a las Cortes de Apelaciones en la inteligencia y aplicación de las leyes y de los vacíos que se noten en ellas y de que se haya dado cuenta al presidente de la República en cumplimiento del artículo $5^{\circ}$ del Código Civil».

35 Soto Delgado (2019) p. 210.

36 Guzmán Brito (2014) pp. 7-19. 
atendido que el director nacional del Sernac es elegido por el Sistema de Alta Dirección Pública y se establecen causales más estrictas de remoción, lo que, en principio, le entrega una mayor independencia. ${ }^{37}$

\subsection{Conciliación voluntaria en materias de interés colectivo o difuso de los consumidores}

De acuerdo al Art. 58, inciso 2º, letra f) de la LPDC, es función del Sernac: «Llevar a cabo el procedimiento consagrado en el párrafo $4^{\circ}$ del Título IV de esta ley». El señalado párrafo regula el "procedimiento voluntario para la protección del interés colectivo o difuso de los consumidores» (arts. $54 \mathrm{H}$ a $54 \mathrm{~S}$ LPDC).

Este procedimiento ha sido creado por la reforma 2018 y permite que el Sernac de oficio, a solicitud del proveedor o de una denuncia fundada de una asociación de consumidores, se inicie un procedimiento voluntario que tiene por objeto «la obtención de una solución expedita, completa y transparente, en caso de conductas que puedan afectar el interés colectivo o difuso de los consumidores». ${ }^{38}$

El procedimiento es voluntario, y conforme al Art. $54 \mathrm{~K}$ inciso $2^{\circ}$ tanto el proveedor como el Sernac, pueden no perseverar en él. Sin embargo, esta norma omite a las asociaciones de consumidores. Creemos que, siendo un procedimiento voluntario, las asociaciones de consumidores tienen igual derecho de desistirse, sin perjuicio que el Sernac pueda continuar de oficio, atendido su función general de protección de los consumidores.

A esta función le denominamos "conciliatoria», porque es un llamado del legislador a que el Sernac pueda facilitar la conciliación extrajudicial, para lo cual procede a reglar el procedimiento de negociación y conciliación. No le denominados «mediación» ya que el Sernac no actúa como tercero neutral y mal podría hacerlo ya que debe cumplir con su obligación legal de siempre velar por los derechos de los consumidores.

El procedimiento es de un plazo acotado de 3 meses, pudiendo prorrogarse por resolución fundada por 3 meses adicionales ${ }^{39}$ y se rige por una serie de principios básicos establecidos expresamente en el art. 54 H LPDC: «indemnidad del consumidor, la economía procesal, la publicidad, la integridad y el debido proceso».

Durante el procedimiento tanto las asociaciones de consumidores como consumidores potencialmente afectados, pueden formular las observaciones que estimen pertinente, con lo cual no se encuentra excluida su participación.

En caso de lograrse un acuerdo, el Sernac pone término al procedimiento voluntario dictando una resolución que establece los términos del acuerdo, y las obligaciones que asumen cada parte participantes del procedimiento voluntario. La resolución, a lo menos, debe recoger los siguientes puntos: ${ }^{40} 1$ ) El cese de la conducta que pudiere haber afectado el interés colectivo o difuso de los consumidores. 2) El cálculo de las devoluciones, compensaciones o indemnizaciones respectivas por cada uno de los consumidores

\footnotetext{
3 Seńalamos «en principio», porque el Servicio Nacional del Consumidor, es uno de los servicios públicos en que el presidente de la República puede remover al director nacional sin expresión de causa, en la medida que cumpla con un determinado número de servicios donde ejercerá esa atribución exclusiva.

38 Art. $54 \mathrm{H}$, inciso 10 de la Ley 19.496 de 1997.

39 Art. 54 J de la ley 19.496 de 1997.

$40 \quad$ Art. 54 P de la Ley 19.496 de 1997.
} 
afectados, cuando proceda. 3) Una solución que sea proporcional al daño causado, que alcance a todos los consumidores afectados y que esté basada en elementos objetivos. 4) La forma en la que se harán efectivos los términos del acuerdo y el procedimiento por el cual el proveedor efectuará las devoluciones, compensará o indemnizará a los consumidores afectados. 5) Los procedimientos a través de los cuales se cautelará el cumplimiento del acuerdo, a costa del proveedor.

La ley, en esta disposición — art. 54 P LPDC— permite, además, que la resolución pueda contemplar «la presentación por parte del proveedor de un plan de cumplimiento, el que contendrá, como mínimo, la designación de un oficial de cumplimiento, la identificación de acciones o medidas correctivas o preventivas, los plazos para su implementación y un protocolo destinado a evitar los riesgos de incumplimiento». ${ }^{41}$

Con la norma recién citada, el legislador está reconociendo el valor de los planes de cumplimiento normativo o "compliance», ${ }^{42}$ que son una innovación reciente en el mundo jurídico, en que se incorporan al interior de las empresas normas de buen gobierno corporativo, y un sistema de cumplimiento efectivo de las mismas por parte de sus integrantes y organización. Esta práctica de preocupación por el cumplimiento de la normativa por parte de la propia empresa objeto de regulación, surge con mayor intensidad después del establecimiento en distintos ordenamientos jurídicos, entre ellos, el chileno, de la responsabilidad penal de las personas jurídicas. ${ }^{43}$

La ley, atendido que se trata de un procedimiento voluntario y, entendemos, como una motivación para participar en él, dispone que la solución propuesta por el proveedor no implicará su reconocimiento de los hechos constitutivos de la eventual infracción, con lo cual se recoge una práctica habitual en materia de transacción.

El acuerdo, recogido en la resolución del Sernac, puede tener efecto erga omnes — como sucede con las sentencias en juicios por interés difuso o colectivo de los consumidores- si el acuerdo es aprobado por el juez competente en lo civil correspondiente al domicilio del proveedor. ${ }^{44}$

El Tribunal debe fallar de plano, y en caso de rechazo, solo podrá interponerse recurso de reposición con apelación subsidiaria. En caso de aprobarse, se produce el efecto erga omnes treinta días después de la publicación de un extracto de la sentencia en un diario de circulación nacional y en el sitio web del Sernac, produciendo el efecto de una transacción extrajudicial respecto de todos los consumidores potencialmente afectados, con excepción de aquéllos que hayan hecho valer sus derechos ante los tribunales con anterioridad, hayan suscrito avenimientos o transacciones de carácter individual con el proveedor o hayan efectuado reserva de sus acciones dentro de los 30 días antes indicados.

En caso que el juez en lo civil, rechace el acuerdo por sentencia ejecutoriada, estimamos que el acuerdo contenido en la resolución del Sernac, es plenamente válido y puede ser ejecutoriado, pero solo con efecto relativo entre las partes que concurrieron al procedimiento. Con lo cual el procedimiento de aprobación,

\footnotetext{
$41 \quad$ Art. 54 P inc. $3^{\circ}$ de la Ley No 19.496 de 1997.

42 Sobre cumplimiento normativo (Compliance) en materia de derecho del consumidor, Del Villar en Boletín Especial de la Academia de Derecho y Consumo (Adeco)-Fundación Fernando Fueyo Laneri, Santiago, 14 de diciembre de 2017, disponible en : http://derechoyconsumo.udp. cl/wp-content/uploads/2017/12/Lucas-del-Villar.pdf ; DEL viLLAR. Sobre cumplimiento normativo en general, Balmaceda Hoyos, Juppet Ewing y Guerra Espinosa (2019).

43 Ley No 20.393 de 2009.

44 Art. 54 Q LPDC.
} 
estimamos que no es requisito para que el acuerdo sea válido, sino que solamente para que tenga efectos erga omnes. ${ }^{45}$

Frente al incumplimiento del acuerdo, tanto con efecto erga omnes o sin él, éste se considera una infracción a la LPDC, con lo cual, además de la exigibilidad de las obligaciones contenidas en el acuerdo, será posible aplicar las multas que contempla la LPDC para infracciones a la ley en el artículo 24 que sanciona las infracciones que no tengan señalada una sanción diferente, como sería este caso, con una multa de hasta 300 unidades tributarias mensuales. Si el proveedor hubiese implementado un plan de cumplimiento normativo y probare su efectiva implementación y seguimiento y, por tanto, el incumplimiento se produjere respecto de punto del acuerdo recogido en la resolución, en tal caso, el proveedor podría acceder a una atenuante en la aplicación de la multa. ${ }^{46}$

Debemos valorar la incorporación por el legislador de este proceso voluntario, ya que siendo de un plazo acotado (tres meses, más tres meses de prórroga), permiten en poco tiempo la búsqueda de una solución voluntaria y que como tal tendrá mayores probabilidades de cumplimiento, por parte de todos quienes intervinieron en esa solución, a diferencia de soluciones impuestas, propias del procedimiento adversarial.

La incorporación de métodos de solución alternativa de controversias, en especial en esta materia de derechos de los consumidores, debe ser siempre bienvenida y es algo respecto de lo cual hemos abogado previamente. ${ }^{47}$ Además, la ley se hace cargo de una situación que inhibía la participación de consumidores en estos procesos voluntarios, ya que de modo de no afectar los derechos potenciales de los consumidores, la ley establece que durante el procedimiento se suspenderá el plazo de prescripción de las denuncias y acciones establecidas en la presente ley durante el tiempo que medie entre la notificación al proveedor de la resolución que da inicio al procedimiento, y la notificación de la resolución de término. ${ }^{48}$

\subsection{Función de supervisión del cumplimiento normativo y legitimación procesal activa en casos de afectación de los intereses generales de los consumidores}

El artículo 58, inciso 2o letra g) de la LPDC, dispone como función del Sernac velar por el cumplimiento de las disposiciones legales y reglamentarias relacionadas con la protección de los derechos de los consumidores y hacerse parte en aquellas causas que comprometan los intereses generales de los consumidores, según los procedimientos que fijan las normas generales o los que se señalen en leyes especiales. La facultad de velar por el cumplimiento de normas establecidas en leyes especiales, incluye la atribución del Sernac de denunciar los posibles incumplimientos ante los organismos o instancias jurisdiccionales respectivas y de hacerse parte en las causas en que estén afectados los intereses generales de los consumidores, según los procedimientos que fijan las normas generales o los que se señalen en esas leyes especiales.

La disposición antes citada, para los efectos de entregar competencia al Sernac para ser legitimado activo se refiere a la protección de "los intereses generales de los consumidores", por lo que es válida la pregunta sobre

45 A vía de ejemplo, revisar resolución que aprueba acuerdo en procedimiento voluntario colectivo entre el Sernac y la empresa de Servicios Sanitarios de Los Lagos S.A., aprobada por 1er Juzgado Civil de Puerto Montt por resolución de 28 de febrero de 2020, rectificada por resolución de 4 de marzo de 2020, Rol V-11-2020, disponible en https://www.sernac.cl/portal/609/articles-56323_archivo_03.pdf.

46 Art. 24 inciso $4^{\circ}$, letra c) de la LPDC.

47 Guerrero Becar pp. 165-185.

48 Art. $54 \mathrm{H}$, inciso final, de la LPDC. Este es un punto que en materia de acciones individuales de los consumidores, en aquellos casos en que se solicitaba la intermediación del Servicio Nacional del Consumidor (o mediación como general y erróneamente se le conoce), conforme al texto original de la Ley 19.496 producía problemas, ya que no consideraba expresamente la suspensión del plazo de prescripción o caducidad de acciones, lo que unido a que además no tenía un plazo máximo, de no arribarse a una solución, el transcurso del tiempo, generaba el riesgo de prescripción o caducidad de algunas de las acciones de los consumidores, p. 177. 
si el Sernac puede actuar en casos en que no esté comprometido el interés general de los consumidores, sino que solo un interés particular o individual. Nuestra opinión es que el texto legal es claro por lo que el Sernac solo puede litigar cuando se trate del interés general de los consumidores o bien cuando la ley le entrega expresamente la posibilidad de hacerse parte, como sucede en el caso de las acciones colectivas.

La calificación de cuando está comprometido el interés general de los consumidores la realizará el propio Sernac, y en caso de controversia frente a la existencia en una causa de dicho interés, entendemos que tal calificación, deberá discutirse en el propio procedimiento judicial, correspondiendo al proveedor demandado reclamar de la falta de legitimación activa del servicio.

El problema se presenta, si se entiende que «el interés general de los consumidores», es equivalente al «interés colectivo o difuso de los consumidores», ya que en el último caso la competencia es de los juzgados civiles por lo que estaría vedada la acción de Sernac ya sea iniciar o hacerse parte en acciones referida a interés individual de un consumidor.

Este es un tema que se ha discutido, decidiéndose en ciertos casos por la Corte Suprema por la vía de queja, considerar que en los casos de interés general de los consumidores debe seguirse la competencia de jueces civiles. ${ }^{49}$ Cabe recordar que la expresión «interés general de los consumidores», en la LPDC, es anterior a la incorporación de las acciones colectivas o de interés difuso, ${ }^{50}$ pero creemos que es posible de ser diferenciadas, si previamente, se realiza una debida categorización del tipo de contravenciones a la ley, entre contravenciones infraccionales, civiles o mixtas. ${ }^{51}$ Para ejemplificar lo antes expresado: si un proveedor no publicita sus precios en sus vitrinas e incluso antes de cualquier acto de consumo, ¿no es posible que el Sernac pueda denunciar a ese proveedor ante el juez de policía local y hacerse parte en ese procedimiento? Creemos que este es un ejemplo en que el Sernac debería actuar por el interés general de los consumidores, sin que sea necesario el ejercicio de una acción colectiva o de interés difuso, porque además no se ha configurado previamente un acto de consumo, pero igualmente su contravención está afectando el interés general de los potenciales consumidores.

\subsection{Atribución para solicitar documentación para fines de fiscalización}

El art. 58, inciso $2^{\circ}$, letra m) de la LPDC, entrega al Sernac la atribución de «solicitar la entrega de cualquier documento, libro o antecedente que sea necesario para fines de fiscalización, procurando no alterar el desenvolvimiento normal de las actividades del afectado».

En esta disposición más que una función — como lo define la ley—es una atribución o potestad para que el Sernac pueda cumplir su función fiscalizadora, por lo que perfectamente pudo quedar comprendida bajo la letra a) del inciso $2^{\circ}$ del artículo 58 de la LPDC función fiscalizadora, sin que se entienda la técnica legislativa de establecerlo como una función autónoma, equivalente a otras de mayor trascendencia.

\footnotetext{
9 Momberg Uribe «La autonomía de la acción en interés general de los consumidores del artículo 58 letra g) de la Ley No 19.496 sobre protección de los derechos de los consumidores (LPC) (Corte Suprema)", en Revista de Derecho (Valdivia), No 24-2, Valdivia, pp. 235-244; De la Maza Gazmuri «De nuevo sobre el interés general de los consumidores», en Mercurio Legal, 4 de octubre de 2017, disponible en http:// www.elmercurio.com/Legal/Noticias/Analisis-Juridico/2017/10/04/De-nuevo-sobre-el-interes-general-de-los-consumidores.aspx.

50 Un interesante trabajo de fichaje en jurisprudencia del uso de las voces interés general, interés difuso o interés colectivo se puede revisar en Contardo González (2016) disponible en versión electrónica en: http://derechoyconsumo.udp.cl/wp-content/uploads/2016/12/El-interés-colectivo-difuso-y-general.pdf.

51 Sobre la posibilidad de clasificar las contravenciones a la LPDC y el efecto de tal distinción, en particular, en materia de diseño normativo que posibiliten incorporar un procedimiento administrativo sancionador en una futura reforma a la LPDC, ver el punto 5 de este trabajo.
} 
Luego de la declaración de inconstitucionalidad de uno de los incisos del artículo 58 LPDC que disponía que la negativa o demora injustificada en la remisión de los antecedentes requeridos en virtud de este artículo, sería sancionada por el Servicio Nacional del Consumidor con una multa de hasta 750 Unidades Tribunales Mensuales, entendemos que en caso de incumplimiento, solo quedará la sanción genérica de la multa establecida en el artículo 24 de la LPDC y previo conocimiento del juez de policía local de la negativa, la que deberá considerarse como una infracción genérica a la LPDC.

Siguiendo una técnica legislativa discutible, el artículo 58 de la LPDC, luego de enumerar todas las funciones del Sernac, en incisos posteriores, desarrolla el ejercicio de esta facultad de solicitar documentación, no entendiéndose por qué el legislador no lo hizo bajo la misma letra q).

En efecto, en los incisos $3^{\circ}$ a $5^{\circ}$ del artículo 57 de la LPDC, el legislador incorpora normas que facilitan el ejercicio de esta atribución, al disponer que (inciso $3^{\circ}$ ) "Los proveedores estarán obligados a proporcionar al Sernac los antecedentes y documentación que les sean solicitados por escrito y que digan relación con la información básica comercial de los bienes y servicios que ofrezcan al público, dentro del plazo que se determine en el respectivo requerimiento, el que no podrá ser inferior a diez días hábiles. También deben proporcionar al Sernac toda otra documentación que se les solicite por escrito y que sea estrictamente indispensable para ejercer las atribuciones que le corresponden al referido servicio, dentro del plazo que se determine en el respectivo requerimiento, que no podrá ser inferior a diez días hábiles. Para dichos efectos el Sernac debe publicará en su sitio web un manual de requerimiento de información, el cual deberá señalar pormenorizadamente los antecedentes que podrán solicitarse, pudiendo el proveedor interponer los recursos administrativos que le franquea la ley.

Luego, la ley deja indemne el derecho del Sernac para poder ejercer su derecho en juicio a solicitar la exhibición o entrega de documentos, conforme a las disposiciones generales y especiales sobre medidas precautorias y medios de prueba, aplicables según el procedimiento de que se trate.

Resulta cuestionable la redacción de esta norma, ya que limita sin sentido el derecho el Sernac en cuanto litigante, ya que lo que parece una reafirmación de sus derechos como tal y que podría ejercer como cualquier litigante, extrañamente, lo limita a «medidas precautorias» y medios de prueba. Sin embargo, entre las medidas precautorias, que se regulan en el Código de Procedimiento Civil, no se contempla la exhibición de documentos, ${ }^{52}$ sino que en las «medidas prejudiciales», por lo señalado, una interpretación literal de la norma, que más allá del error o ignorancia procesal manifiesta de quienes redactaron esta norma, es la que corresponde aplicar como fórmula interpretativa atendido que la ley es específica y clara en su tenor al referirse a «medidas precautorias», conllevará a que si el Sernac requirió directamente documentación al proveedor, previo al juicio, tanto que sea distinta a la que quiera se exhiba en juicio o incluso sea la misma, pero que el proveedor se negó a entregarla, pues, en esos supuestos aplicando literalmente esta norma el Sernac no podrá solicitar la exhibición de documentos de acuerdo a las reglas generales de procedimiento como medida prejudicial ${ }^{53}$ y solo podrá solicitarlo dentro de la prueba documental una vez notificada la demanda, con el riesgo de pérdida de la documentación sensible para el caso.

52 Las medidas precautorias están reguladas en los Arts. 290 y 302 del Código de Procedimiento Civil, en cambio las medidas prejudiciales lo están en los Arts. 273 a 289 del Código de Procedimiento Civil. No cabe confundir lo dispuesto en el Art. 302 del Código de Procedimiento Civil, sobre las denominadas «medidas prejudiciales precautoria», ya que se trata de medidas precautorias que se pueden solicitar antes de notificar la demanda, esto es como prejudiciales, pero no se trata de medidas prejudiciales que se puedan interponer como precautoria (entre las cuales no está la exhibición de documentos).

53 Art. 273 números 3 y 4 del Código de Procedimiento Civil. 
Por último, en esta materia, el artículo 58 de la LPDC dispone que «el juez de policía local puede ordenar la incautación de la documentación requerida». Entendemos que la ley se refiere a aquella documentación que solicita el Sernac en ejercicio de su función fiscalizadora, y no aquella que solicite en juicio, porque en ese caso deben aplicarse los mecanismos de apremio establecidos en los respectivos procedimientos, sin que sea necesaria esta norma.

\subsection{Atribución para celebrar convenios con municipalidades}

El art. 58 inciso $2^{\circ}$, letra n) de la LPDC dispone como función del Sernac, lo más bien es una atribución, la de "Celebrar convenios con municipalidades para que éstas coordinen y gestionen las audiencias de conciliación obligatorias respecto de los casos de denuncias presentadas en defensa del interés individual».

Más que una función, en este caso se entregan atribuciones o potestades al Sernac, pero esta norma incorporada en la Ley 21.081 de 2018, estimamos que ha quedado convertida en letra muerta, ya que el artículo 50 G que contemplaba el proyecto de ley, fue declarado inconstitucional. Dicho artículo se refería al procedimiento sancionatorio ante el Sernac por el cual el consumidor podía optar en casos de afectación de su interés individual, entre acudir al juzgado de policía local o bien seguir un procedimiento administrativo que contemplaba una etapa conciliatoria, en que las denuncias formuladas por el consumidor se pondrían en conocimiento del proveedor a fin de que éste propusiera alternativas concretas de solución o corrección al hecho denunciado, respuesta que debería efectuar por escrito dentro de los siete días hábiles siguientes de recibida la comunicación. Pues bien, si la norma vigentepermite celebrar convenios con municipalidades para el solo efecto de las conciliaciones obligatorias, y hoy esas conciliaciones no están contempladas en la ley — se excluyen las propias del procedimiento judicial ya que esas las realiza el tribunal— no se entiende el actual sentido de esta disposición.

Lo más grave de esta norma, que luego de la declaratoria de inconstitucionalidad queda asistemática, es probablemente un efecto no deseado por el legislador, ya que en definitiva se restringen los convenios del Sernac con municipalidades solo a conciliaciones obligatorias que no existen, pero además, a contrario, la ley no permitiría suscribir convenios con municipalidades con otros fines, por lo que pueden ser perfectamente cuestionados convenios referidos a conciliaciones voluntarias, mediaciones u otras actividades que han realizado oficinales municipales en apoyo de los consumidores.

Lo anterior lo mencionamos ya que una de las funciones del Sernac, quizás la más conocida por los consumidores, era la de actuar como facilitador de la solución, lo que erróneamente se conocía como «mediación del Sernac», y que estaba contemplada en la LPDC previo a la reforma de la Ley 21.081 de 2018 en el artículo 58 inciso $2^{\circ}$ letra f), norma luego de la reforma, se elimina. En efecto, el texto de la LPDC establecía como una atribución del Sernac:«Recibir reclamos de consumidores que consideren lesionados sus derechos y dar a conocer al proveedor respectivo el motivo de inconformidad a fin de que voluntariamente pueda concurrir y proponer las alternativas de solución que estime convenientes. Sobre la base de la respuesta del proveedor reclamado, el Servicio Nacional del Consumidor promoverá un entendimiento voluntario entre las partes. El documento en que dicho acuerdo se haga constar tendrá carácter de transacción extrajudicial y extinguiráa una vez cumplidas sus estipulaciones, la acción del reclamante para perseguir la responsabilidad contravencional del proveedor». Esta norma en el proyecto de ley aprobado por el Congreso en el año 2017 se eliminó como función específica del Sernac, ya que se le incorporaba en el procedimiento sancionatorio del Art. 57 H, que contemplaba la etapa de conciliación obligatoria. Sin embargo, al ser declarado inconstitucional el procedimiento sancionatorio — sin reponer esta función en el art. 58 de la LPDC- conlleva a que, en sentido estricto, el Sernac ya no cuenta con competencia legal para ejercer esta función conciliatoria — que se le denominaba erróneamente 
mediación— ${ }^{54}$ y mal podrá delegarla mediante un convenio a una municipalidad o cualquier otro organismo, ya que la ley lo restringe a conciliaciones obligatorias, lo que nos hace adelantar que sin perjuicio de reconocer que probablemente en la práctica el Sernac seguirá en los hechos realizando una actividad de promover entendimiento,resultará indispensable velando por el cumplimiento del principio de legalidad poder avanzar en una «reforma a la reforma». ${ }^{55}$

\section{Posibilidad de introducir en una futura reforma funciones sancionadoras}

Es probable que el entusiasmo para transformar al Sernac en un «León con dientes», haya llevado a frustrar la intención inicial al incorporar en las reformas materias que fueron declaradas inconstitucionales ${ }^{56}$ particularmente en materia normativa y sancionatoria. Estimamos que esto se pudo evitar si se hubiese realizado por el legislador una distinción entre los distintos tipos de contravenciones, esto es, distinguir por el legislador contravenciones a la LPDC de tres naturalezas distintas las propiamente administrativas, las propiamente civiles y aquellas que son de naturaleza mixta. Las contravenciones administrativas o infracciones propiamente tales y que se refieren a la inobservancia o deberes legales impuestos a los proveedores; las contravenciones civiles representan un incumplimiento contractual; y las mixtas serán aquellas en que un mismo hecho genere contravenciones administrativas y civiles. ${ }^{57}$

Estimamos que las contravenciones propiamente infraccionales, esto es, que un proveedor incurre en una contravención a la ley aún ex antes de celebrar cualquier acto de consumo, existiendo consumidores potenciales como, por ejemplo, infracciones a la rotulaciones de productos o a la exhibición de precios, dichas contravenciones, sin cuestionamiento de constitucionalidad, perfectamente podrían ser conocidas en un procedimiento administrativo sancionador ante el Sernac, estableciendo como en otros procesos administrativos ante Superintendencias u órganos reguladores, un recurso de apelación o de legalidad ante un órgano jurisdiccional.

La Ley 21.081 en su texto aprobado por el Congreso Nacional, no realizó esta distinción y toda infracción a la Ley 19.496 era susceptible de un procedimiento administrativo sancionador, incluyendo por ejemplo una contravención propiamente civil como puede ser una causa por garantías legales o de indemnización, lo que el Tribunal Constitucional estimó que era materia de los órganos jurisdiccionales, esfumándose la pretensión de dotar de facultades sancionadoras al Sernac, que creemos podría incorporarse en una futura reforma a la lpdc si se restringe a las contravenciones propiamente administrativas.

\section{Conclusiones}

6.1. Luego de la reforma a la LPDC introducida por la Ley No 21.081 de 2018, y su controvertida tramitación, en particular con la declaración de inconstitucionalidad de una serie de funciones que se le

54 Una mediación requiere de un mediador tercero neutral, y mal podía serlo el Sernac, ya que en el caso de no arribar a un acuerdo, podía ejercer acciones en contra del proveedor en defensa del interés general de los consumidores.

55 En sentido contrario se pronuncia Soto, quien estando de acuerdo en que la facultad de mediación quedó derogada expresamente en la Ley 19.496, estima que igualmente el Sernac puede desempeñar la función conciliatoria , recibiendo reclamos y trasladándolos al proveedor para promover un entendimiento atendidas las potestades implícitas del Sernac. Soto Delgado p. 231.

56 Sentencia del Tribunal Constitucional de fecha 18 de enero 2018, Rol 4012-2017.

57 Guerrero Becar, pp. 433-453. En el mismo sentido de poder clasificar las infracciones o contravenciones a la lpdc, entre otros: Pinochet Olave en Elorriaga De Bonis (2012) pp. 427-433; Barcia Lehmann en De la Maza Gazmuri y Pizarro Wilson (2013) pp. 607-648, Contardo González en Revista de Derecho Público Iberoamericano, núm. 3, Santiago (2013) pp.217; Isler Soto en Revista Chilena de Derecho y Ciencia Politica, mayo-agosto, vol. 6, № 2, Santiago, (2015) pp. 75-92. Antes, desde la perspectiva de la calificación de las acciones que emanan de la LPDC: Cortez Matcovich p. 23. 
entregaban a Sernac en el proyecto originalmente aprobado por el Congreso y que le permitían normar, investigar y juzgar, cabe igualmente valorar las nuevas atribuciones con las que se dota al Sernac, que le permiten contar con mayores funciones y atribuciones para cumplir su rol de protección de los derechos de los consumidores.

6.2. Las reformas introducidas, permiten al Sernac sumar funciones y atribuciones, que retrospectivamente le acercan a aquellas que en su origen contaron sus antecesores institucionales como lo fueron los Comisariatos, Superintendencia y Dirinco, según revisamos inicialmente, lo que no deja de ser paradójico, ya que es avanzar para retroceder en el tiempo, ya que implica introducir facultades que tuvo en su origen.

6.3. Las nuevas funciones introducidas por la Ley No 21.081, en particular las facultades de fiscalización, interpretación administrativa, y de conciliación en procedimientos de interés colectivo o difuso que pueden producir efecto erga omnes si luego son aprobados por un Juzgado Civil, todo ello unido al aumento en la cuantía de las sanciones que pueden aplicar los tribunales de justicia, debe reconocerse con un gran avance para la protección de los derechos de los consumidores.

6.4. Las nuevas funciones permiten al Sernac tener un rol mucho más activo en la defensa de los consumidores, lo que rompe el paradigma instaurado desde 1974 con el Decreto Ley No 280, que luego recogió la Ley No 18.223 y finalmente en el texto original de la Ley No 19.496, que cuanto el diseño normativo apuntaba a que la carga de la persecución de contravenciones a la LPDC quedaba en manos de los propios consumidores, limitándose la acción directa de Sernac.

6.5. Es posible dotar en el futuro de facultades sancionadoras al Sernac, en la medida que el procedimiento contencioso administrativo que se establezca se restrinja a investigar y sancionar contravenciones propiamente infraccionales a la LPDC, esto es, aquellas en que un proveedor incurre aún sin que exista un acto de consumo, propuesta que se deja planteada para su discusión doctrinal en vistas a una futura reforma a la LPDC.

\section{Bibliografía Citada}

Alvear, Julio (2018): “¿Ogro filantrópico o Sernac?, en Mercurio Legal de 2 de febrero de 2018.

Balmaceda Hoyos, Gustavo, Juppet Ewing, María Fernanda y Guerra Espinosa, Rodrigo: Compliance: Visión general desde una perspectiva penal y comercial, Thomson Reuters, Santiago, 2019.

Barcia Lehmann, Rodrigo (2013): «Artículo 26: Prescripción responsabilidad contravencional», en De la Maza Gazmuri, Íñigo y Pizarro Wilson, Carlos (directores): La protección de los derechos de los consumidores (Santiago, Thomson Reuter).

Contardo González, Juan Ignacio (2013): «Comentario de sentencia Sernac con Cencosud», en Revista de Derecho Público Iberoamericano, núm. 3, (Santiago,2013).

Contardo González, Juan Ignacio (director) (2016): Fichaje de sentencias, el interés colectivo, difuso y general en el derecho privado del consumo, (Santiago, Academia Derecho y Consumo, Universidad Diego Portales), disponible en versión electrónica en: http://derechoyconsumo.udp.cl/wp-content/ uploads/2016/12/El-interés-colectivo-difuso-y-general.pdf.

Cordero, Luis (2017): «Jurisdicción en la Administración: una tramposa confusión» en Mercurio Legal de 30 de octubre de 2017, disponible en http://www.elmercurio.com/Legal/. 
Cordero, Luis (2018): «El problema de identidad del Derecho Administrativo chileno» en Mercurio Legal de 27 de febrero de 2018, disponible en http://www.elmercurio.com/Legal/.

Cortez Matcovich, Gonzalo (2004): El nuevo procedimiento regulado en la Ley $N^{\circ} 19.496$, (Santiago, Lexis Nexis).

De la Maza Gazmuri, Ińigo (2017): «De nuevo sobre el interés general de los consumidores», en Mercurio Legal, 4 de octubre de 2017, disponible en disponible en http://www.elmercurio.com/Legal/.

Del Villar, Lucas: «Planes de Cumplimiento en la reforma a la Ley No 19.496» en Boletín Especial de la Academia de Derecho y Consumo (Adeco)-Fundación Fernando Fueyo Laneri, Santiago, 14 de diciembre de 2017, disponible en: http://derechoyconsumo.udp.cl/wp-content/uploads/2017/12/ Lucas-del-Villar.pdf

Guerrero Becar, José Luis (2005): "Acciones de interés individual en protección al consumidor en la Ley No 19.496 y la incorporación de mecanismos de resolución alternativa de conflictos», en Revista de Derecho de la Pontificia Universidad Católica de Valparaiso, núm. 26, pp. 165-185.

Guerrero Becar, José Luis (2008): «La distinción entre contravención infraccional e incumplimiento contractual o contravención civil en materia de protección de derechos del consumidor», en Guzmán Brito, Alejandro (editor): Colección de estudios de Derecho civil en homenaje a la profesora Inés Pardo de Carvallo, (Valparaíso, Ediciones Universitarias de Valparaíso), pp. 433-453.

Guzmán Brito, Alejandro (2014): La interpretación administrativa en el derecho chileno, (Santiago, Legalpublishing - Thomson Reuters).

Isler Soto, Erika (2015): «Las normas que dan origen a la responsabilidad civil y a la responsabilidad infraccional en la Ley 19.496», en Revista Chilena de Derecho y Ciencia Politica, mayo-agosto, vol. 6, No 2, pp. 75-92.

Momberg Uribe, Rodrigo (2011): «La autonomía de la acción en interés general de los consumidores del artículo 58 letra g) de la Ley No 19.496 sobre protección de los derechos de los consumidores (LPC)» (Corte Suprema), en Revista de Derecho (Valdivia), No 24-2, Valdivia, pp. 235-244.

Muñoz Machado, Santiago (director) (2017): Diccionario Panhispánico del español jurídico, T. 1, Real Academia Española, (Madrid, Santillana).

Pinochet Olave, Ruperto (2012): «¿Es la condena infraccional requisito de la indemnización de perjuicios regulada en la Ley N ${ }^{\circ} 19.496$ sobre Protección del Consumidor? Un error histórico», en Elorriaga De Bonis, Fabián (coord.), Estudios de Derecho Civil VII, (Santiago, Abeledo Perrot-Legal Publishing).

Soto Delgado, Pablo (2018): «El Tribunal Constitucional y las sanciones administrativas en el fallo sobre el Sernac», en Mercurio Legal de 19 de enero de 2018, disponible en http://www.elmercurio.com/ Legal/

Soto Delgado, Pablo (2019): «La potestad del Sernac para recibir reclamos y promover acuerdos individuales luego de ser eliminada por el Tribunal Constitucional», en Revista de Derecho Universidad de Concepción, No 245, Concepción, 2019, pp 201-234.

Vergara, Alejandro (2018): «Sanciones, despotismo e identidad del derecho administrativo», en Mercurio Legal de 20 de marzo de 2018, disponible en http://www.elmercurio.com/Legal/.

\section{Normas citadas}

Decreto Ley No 520 (31.08.1932) Crea el Comisariato General de Subsistencias y Precios.

Decreto con Fuerza de Ley No 173, Ministerio de Hacienda (31.07.1953) Determina atribuciones de la Superintendencia de Abastecimientos y Precios. 
Ley No 10.336 (29.05.1952) Ley Orgánica de la Contraloría General de la República.

Decreto Economía No 1262, (30.12.1953) Fija el texto refundido de la ley de organización y atribuciones de la Superintendencia de Abastecimientos y precios.

Decreto con Fuerza de Ley No 242, Ministerio de Economía (06.04.1960) Aprueba Ley Orgánica del Servicio Nacional del Consumidor

Decreto Ley No 211 (22.12.1973) Fija normas para la defensa de la libre competencia.

Decreto Ley No 280 (24.01.1974) Establece normas en resguardo de la actividad económica nacional.

Ley No 18.223 (10.06.1983) Establece normas de protección al consumidor y deroga Decreto Ley n² 280 , de 1974.

Ley No 18.959 (24.02.1990) Modifica, interpreta y deroga normas que indica.

Ley No 19.496 (07.03.1997) Establece normas sobre protección de los derechos de los consumidores.

Ley No 19.955 (14.07.2004) Modifica la ley no 19.496 sobre protección de los derechos de los consumidores.

Ley No 20.393 (02.12.2009)Establece la responsabilidad penal de las personas jurídicas en los delitos de lavado de activos, financiamiento del terrorismo y delitos de cohecho que indica.

Ley No 21.081 (13.09.2018) Modifica Ley n 19.496, sobre protección de los derechos de los consumidores.

Resolución Exenta No 370 (23.04.2020) del Director del Servicio Nacional del Consumidor, Aprueba la Política de Fiscalización del Servicio Nacional del Consumidor.

\section{Jurisprudencia citada}

Tribunal Constitucional, Rol 4012-2017 (18.01.2018).

Tribunal Constitucional, Rol 4727/2018 (05.07.2018).

1er Juzgado Civil de Puerto Montt, Rol V-11-2020 (28.02.2020 y 04.03.2020) 